\title{
Bend Radius Analysis for Water Monitor in Capstone Design Project
}

\author{
Alamgir Choudhury, Ph.D. and Jorge Rodriguez, Ph.D. \\ Western Michigan University, Department of Engineering Design, Manufacturing, and Management Systems \\ (EDMMS), alamgir.choudhury@wmich.edu,jorge.rodriguez@wmich.edu
}

\begin{abstract}
To be effective, a fire fighting water monitor needs to be able to pump water onto the fire at a very high rate. Most of the commercially available water monitors pump up to 2500 gallons per minute (GPM) of water. Developing cost- effective solutions of high capacity flow systems translates directly into saving of property and life. Currently, the largest commercial monitors have a four-inch outlet diameter. The goal for this project is to design a monitor with a six-inch diameter outlet that can pump at least 3,000 GPM. This would allow fire fighters to pump considerably more water in a shorter period of time, in turn, save money, time, and prevent distresses in already affected families and businesses. Based on research on current commercially available monitors and other similar systems, it was decided to investigate the effect of bend radii on performance of an existing monitor. Computational Fluid Dynamics (CFD) and Finite Element Analysis (FEA) tools were used to predict how geometry designs and materials can be optimized in order to minimize pressure loss and withstand the effect of higher water pressure. Analyses were done for various raddi (R1 and R2), and the results led to the design of a six-inch water monitor, with a $34 \%$ improvement in pressure loss. Initial test results have been successful, and commercial production has been approved, thus confirming the validity of the design proposed in this project.
\end{abstract}

Keywords-Water Monitor, CFD, FEA, Capstone Project.

Digital Object Identifier (DOI):

http://dx.doi.org/10.18687/LACCEI2016.1.1.365

ISBN: 978-0-9822896-9-3

ISSN: $2414-6390$

$14^{\text {th }}$ LACCEI International Multi-Conference for Engineering, Education, and Technology: "Engineering Innovations for Global Sustainability”, 20-22 July 2016, San José, Costa Rica. 


\title{
Bend Radius Analysis for Water Monitor in Capstone Design Project
}

\author{
Alamgir Choudhury, Ph.D. and Jorge Rodriguez, Ph.D. \\ Western Michigan University, Department of Engineering Design, Manufacturing, and Management Systems (EDMMS), \\ alamgir.choudhury@wmich.edu,jorge.rodriguez@wmich.edu
}

\begin{abstract}
To be effective, a fire fighting water monitor needs to be able to pump water onto the fire at a very high rate. Most of the commercially available water monitors pump up to 2500 gallons per minute (GPM) of water. Developing costeffective solutions of high capacity flow systems translates directly into saving of property and life. Currently, the largest commercial monitors have a four-inch outlet diameter. The goal for this project is to design a monitor with a six-inch diameter outlet that can pump at least 3,000 GPM. This would allow fire fighters to pump considerably more water in a shorter period of time, in turn, save money, time, and prevent distresses in already affected families and businesses. Based on research on current commercially available monitors and other similar systems, it was decided to investigate the effect of bend radii on performance of an existing monitor. Computational Fluid Dynamics (CFD) and Finite Element Analysis (FEA) tools were used to predict how geometry designs and materials can be optimized in order to minimize pressure loss and withstand the effect of higher water pressure. Analyses were done for various raddi ( $\mathrm{R} 1$ and $\mathrm{R} 2$ ), and the results led to the design of a six-inch water monitor, with a $34 \%$ improvement in pressure loss. Initial test results have been successful, and commercial production has been approved, thus confirming the validity of the design proposed in this project.
\end{abstract}

\section{Keywords-Water Monitor, CFD, FEA, Capstone Project.}

\section{INTRODUCTION}

There are a number of commercial designs of water monitor available in the market. Their capacity varies from few hundred gallons to thousands of gallons per minute (GPM) of water discharged. Elkhart Brass has been producing equipment for the firefighting industry for over 110 years. Many of their designs have had great success in the market and the company continues to push the envelope with new products. All Elkhart Brass designs [1] have fully enclosed and sealed gear cases and have built in override devices (hand wheel or override nut). Cobra EXM (Fig. 1) is designed to be used on pumper and aerial trucks in the field. The inlet of monitor varies from 3.5 to 4 inch in diameter with maximum flow rate of $1500 \mathrm{GPM}$ at an operating pressure of 500 psi. The monitors are made of hard anodized aluminum alloy, and its surface is Teflon impregnated. The waterway is vaned and goes from a circular waterway to an ellipse when making a hard turn. The goal of these features is to improve the flow
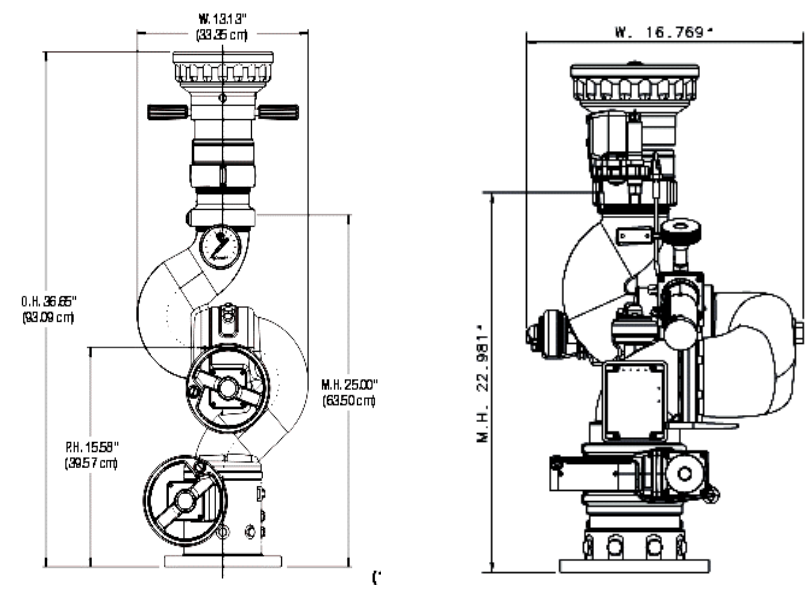

Figure 1. Configurations for Cobra and SpitFire monitors.

and reduce friction loss. At 1500 GPM, it has a $30 \mathrm{psi}$ pressure drop from the inlet of the monitor to outlet. SpitFire (Fig. 1) is constructed of caste brass and has an inlet of 4 inches and an outlet of 3.5 inches with maximum flow rate of 2,000 GPM and an operating pressure of $250 \mathrm{psi}$. It also has a fully vaned waterway with a pressure loss of 39 psi. It has both, manual and electronic control of guidance of water jet. It is designed for use in industrial applications where salt water and other corrosive materials may be a factor. The Scorpion EXM monitor is also a similar product with a four inch inlet a 3.5 inch outlet. The max flow rate of the Scorpion is 2500 GPM and can operate at a maximum pressure of 250 psi with a pressure loss of just under 60 psi. This monitor is available with only remotely control electronic motors for pumper trucks and de-icing vehicles.

Akron Brass has numerous monitors that we can compare and research. However, when it comes to competitors designs, we are limited with the information that they feel comfortable making public. This situation makes the comparison and research aspect more difficult. It was decided to limit the research to just a few of Akron Brass' monitors. The Style 3690 Storm Monitor [2] features a 5-inches nozzle and allows for full 360 degree rotation. The vertical travel for this monitor goes from +85 degrees to -45 degrees for a total range of 130 degrees. It is made out of brass with a capacity

Digital Object Identifier (DOI): http://dx.doi.org/10.18687/LACCEI2016.1.1.365 ISBN: 978-0-9822896-9-3

ISSN: $2414-6390$

$14^{\text {th }}$ LACCEI International Multi-Conference for Engineering, Education, and Technology: "Engineering Innovations for Global Sustainability”, 20-22 July 2016, San José, Costa Rica. 


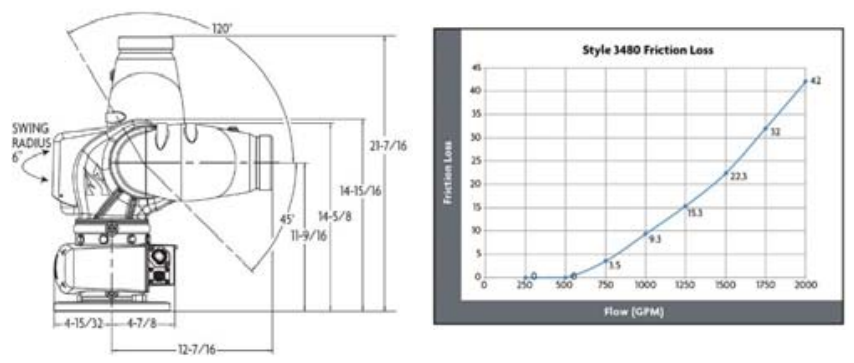

Figure 2. StreamMaster II 3480 monitor and friction loss.

of 2,000GPM and is controlled with hand wheels. StreamMaster II (Fig. 2) is another water monitor from Akron Brass Company [3]. It has a 6-inch operating envelope which is very compact in its current design. This monitor can flow up to 2,000 GPM and allows almost a full rotation (355 degrees) and an elevation range of 165 degrees; ranging from +120 degrees to -45 degrees. The StreamMaster II monitor also features a waterproof control system which allows the user to be at a safe distance when operating the monitor with the use of a hand-held remote. The friction loss for this design ranges from (almost) 0 psi at 250 GPM, up to 42 psi at 2,000 GPM which is shown in the graph to the right in Fig. 2. It has an outlet nozzle that ranges from 2.5 to 3.5 inches and works as a 12 or 24 Volt unit. The overall dimensions of the design are shown in the figure, with the full range of motion in the vertical direction being illustrated as well. This monitor is made out of Pyrolite, which is very lightweight.

Williams Fire is a relatively younger company; they have only been around since 1980 but have quickly gained respect in the industry with their new designs and technical improvements. Williams Fire has one of the few 6-inch monitors that are on the market today. By far, the most powerful monitor that Williams Fire has on the market is the Direct-Mount Electric Actuated Monitor [4]. It offers either a 6- or and 8-inch nozzle, and can pump water or foam up to 6,000 GPM. This monitor is controlled remotely which allows for safe operating of the monitor. It offers a 360 degree horizontal rotation and a -70 degrees to +70 degree vertical travel. It ranges from a wide fog to a straight stream water flow. The monitor and its controls are designed to work in conditions as low as -20 degrees Fahrenheit and at a maximum working pressure of 200 psi. The pressure drop in the 6-inch monitor is 16.7 psi at 3,000 GPM and 21.2 psi at 6,000 GPM for the 8-inch monitor. The monitor is made of stainless steel and the other components are made from bronze and nickel plated brass. Model 5 Water Powered Oscillating Monitor [5] is a high flow type (750 to 1500 GPM). The oscillating mechanism is driven by a water drive wheel that is connected to a double reduction gearbox. The monitor ranges from +80 degrees to -40 degrees vertically and allows for full 360 degree rotation horizontally. It has a 4-inch nozzle and has a pressure loss from approximately 0 psi at 435 GPM to 13 psi at 1500 GPM.

This report presents performance analysis challenges while improving the engineering design of a water monitor for firefighting application. The project was sponsored by a local water monitoring company, who provided technical assistance as well as fabrication and financial support. The quality of senior design projects at Western Michigan University is highly regarded by local industry, who sponsors the majority of the capstone projects undertaken every semester. Generally faculty present project ideas to the students, and each student indicates any interest on specific projects. Similarly, a student or students can approach a faculty member in order to have a technical advisor that collaborates in an industry sponsored project. Prior exposure of some of the students in the group with design of similar products, and the interest and motivation to perform design improvements to the present system are the deciding factors to define the project.

\section{Problem StATEMENT}

Currently these monitors are offered to OEM fire truck manufacturers and industrial fire protection industries in the United States with a wide variety of options capable of spraying large volumes of water at a very high rate of speed. However, the monitors are limited to a flow of 2500 GPM; there are several markets, primarily in Asia, that are interested in getting the highest possible flow on its various fire apparatus. In the foreign marketplace, desire of the customer is to get the maximum amount of water pushed as far as possible while complying with minimum space requirements. The market demands that there be a small, compact, lightweight, large-flow monitor that can be mounted on the top of a fire truck or end of an aerial ladder and deliver water using a pump that does not have huge power and space requirements [6]. Due to the huge growth in the Asian markets, fire truck manufacturers are looking to serve these customers in as fast as possible. This means supplying rescue, aerial, pumper, and airport rescue/ firefighting trucks that meet the needs of the customer. This includes building trucks with larger pump capacity to meet the high flow requirements of the customer. The truck manufacturers need a monitor to pair with their trucks and the pumps used in them in order to deliver what the customer requires.

There is an interest to bring to market a new monitor that will flow over 3,000 GPM, but be more compact than any of their prior monitors pumping over 2,000 GPM. By offering a monitor with more flow and a lightweight, small physical working envelope, the expectation is to further increase market share primarily in foreign markets. Another application the new monitor could be used for is within industrial fire protection systems. These systems are typically multi-monitor systems that are all controlled at one or more remote locations. These monitors, unlike when used onboard

14 ${ }^{\text {th }}$ LACCEI International Multi-Conference for Engineering, Education, and Technology: "Engineering Innovations for Global Sustainability”, 20-22 July 2016, San José, Costa Rica. 
a fire truck, are primarily used to blanket an area or object with water or fire-retardant foam. This application requires that the monitor withstand harsh weather conditions and be able to withstand prolonged use at maximum pressure and flows. The monitor must also be made of a material compatible with environmental hazards and chemicals, as well as any chemicals that are used to create fire retardant foam.

\section{PRoject OBJectives}

The objective for the project were established in consultation with the industrial partner supporting the project. The main objectives was to come up with a series of designs encompassing the flow rate, pressure loss, and flow capacity that will result in a wider spectrum of offerings by the sponsoring company. Such spectrum of offerings will results in an increase of the market share the company has in this specialized market.

After background research, those designs would be analyzed in order to compare their main features and performance with that of existing designs in the market. The best option would be then selected for development of the detailed design. It was decided, together with the manufacturer of the water monitors sponsoring this senior design project, to define the requirement of working on a sixinch one with the following characteristics:

- Improve flow rate over other existing products

- Less pressure loss at comparable flow rates

- Less turbulent flow over current products

- Keep overall envelope size to a minimum

- Prototype monitor should move at comparable speed.

The complete project encompassed implementation of the proposed design by fabrication of required prototype and testing to measure their performance. Fabrication of the proposed prototype implies to make a core for casting the monitor body, machine the core to specified dimensions, and assemble all components. Most of the other components would be acquired, like the nozzle for the monitor, or retrofitted from other monitors. All testing would be performed at the sponsor's test facility.

\section{CONSTRAINTS AND REQUIREMENTS}

As it is expected in engineering design projects, this new sixinch water monitor needs to fulfill several constraints, thus making it a constraint-based design project. The design constraints specified for this project are:

a. Functionality. The primary intended application will require the monitor to serve as deck guns and as aerials. The monitor should withstand vibrations experienced during typical travel while mounted on truck.

$b$. Environmental Conditions. The monitor will need to withstand temperatures from $-40 \mathrm{~F}$ to $185^{\circ} \mathrm{F}$. The material of the body of the monitor will be hard coated aluminum. Plastic components must be protected from UV degradation. The monitor must be capable of interacting with various foam solutions. The monitor will comply with, at minimum, NEMA 4, an electronic water test.

c. Control. The mechanical controls will provide manual overrides for all monitors as well as providing hand wheel controls as an option that will not spin while on operation. The existing EXM controls will be provided as the electrical controls.

d. Operation. The monitor will have a flow of at least 3,000 GPM, have a maximum friction loss of $18 \mathrm{psi}$ at the rated flow of 3,000 GPM. The maximum working pressure will be 250 psi and have a static pressure of $500 \mathrm{psi}$. In the power transmission, it will be important to avoid any additional gears and gear cases. O-ring seals will be used to seal the rotational joints to prevent grease from escaping during operation. The electrical components will require absolute position sensing. e. Loading. The monitor will need to be able to withstand crashing into itself, without damage, and surrounding objects under own power, stall current. The design will be analyze using the Finite Element Analysis (FEA) option in SolidWorks to test at what point the gear teeth break (torque), how much weight can be supported by the monitor (weight/torque), and to test how high the water can be pressurized (pressure). The monitor must be tested to ensure all fasteners hold securely as intended as well as under the vibration it will experience as specified above.

f. Expected Product Lifecycle. The monitor must be able to cycle vertically and horizontally under pressure (250 PSI) for at least 10,000 cycles. The lifecycle for the monitor is 10 years. The monitor will have a two year warranty for the electrical components and a 5 year warranty for the mechanical components.

g. Power Source. The monitor will have an operating voltage from 11 to 32 volts DC), and be J1939 compliant. Its intended operation power will be both 12 and 24 volts DC.

$h$. Maintenance. There will be minimal lubrication required as outlined in the installation and maintenance documentation. The manufacturer will provide individual part replacement of minor parts and accessories in event of damage as well as provide parts kit before release for regularly worn parts.

i. Mating Requirements. The intake of the monitor will be compatible with a 6" ANSI flange. The discharge end of the monitor will fit a 6" hose thread.

j. Accessories. There will be room to add gages, light kit, switch kit, antenna (mounting area is required) as well as being compatible with various nozzles

$k$. Mobility. The monitor will be required to possess a vertical travel from -50 to +120 degrees with respect to ground (0 degrees) and a horizontal travel from -90 to +90 degrees with respect to a chosen center position. There is a preferred horizontal rotation of 360 degrees. The minimum speed will be $0.8 \mathrm{rpm}$ with a maximum speed of $3.0 \mathrm{rpm}$ (both horizontally and vertically).

$14^{\text {th }}$ LACCEI International Multi-Conference for Engineering, Education, and Technology: "Engineering Innovations for Global Sustainability”, 20-22 July 2016, San José, Costa Rica. 
l. Size/Weight. The radius of the monitor will not exceed 8”. The maximum swing radius is 6" for 180 degree rotation. This means that the monitor cannot cross an invisible plane positioned 6" behind the center of its base. The maximum overall dimensions are as follows: length of 24", width of 24", and height of 36 ". Stow height is not to exceed 16 " and the monitor will weigh less than 50 pounds.

$m$. Aesthetics. The monitor is required to include a component that allows it to be recognized as a specific product of the sponsor. The monitor will be colored with an anodized aluminum and have black accents. The design will need to show improvement from the existing EXM monitors by reducing the visible wires as well as other aspects. The monitor's motors will need to be protected by coverings. The monitor will include a metal nameplate displaying monitor/catalog name fastened with screws. It will also have a metal nameplate specifically for prototype monitors and it will display intellectual property numbers or symbols, and certifications and standards achieved.

$n$. Assembly. The design will limit the number of different fasteners used, provide adequate room for harness and wiring, include torque specs for all pertinent fasteners, and the prints will provide all needed instructions or reference other valid documents for assembly.

o. Component Selection. The harness will limit coiled type harnessing. The motors will be upgradable/interchangeable with industrial grade motors and the position sensors will be chosen based on the least costly option that still provides all the existing information.

\section{DEVELOPMENTAL WORK}

Based on research on current monitors presented above, and the expected market demand, the development of the sixinch monitor model started. The water flow path contour was defined by using a combination of circular arcs. After a topology for the monitor has been established, the use of Finite Element Analysis (FEA) and Computational Fluid Dynamics (CFD) packages will be used to perform desktop testing. The designs will be tested in order to ensure that it will be suitable for its intended purposes described in the design constraints. An existing monitor would be used for all reference measurements. Once the system model is developed and analyzed for its performance, the final detail engineering will be carried out, and castings will be made to create a prototype. This prototype of the monitor will be tested to ensure that its efficiency and performance are as specified.

\section{CONCEPTUAL MODEL}

Once a design criteria has been establishes, the important topological features of current monitors were identified to develop a solid model of a six-inch diameter water monitor. The development was done using a professional version of SolidWorks. The solid models was used to analyze water flow
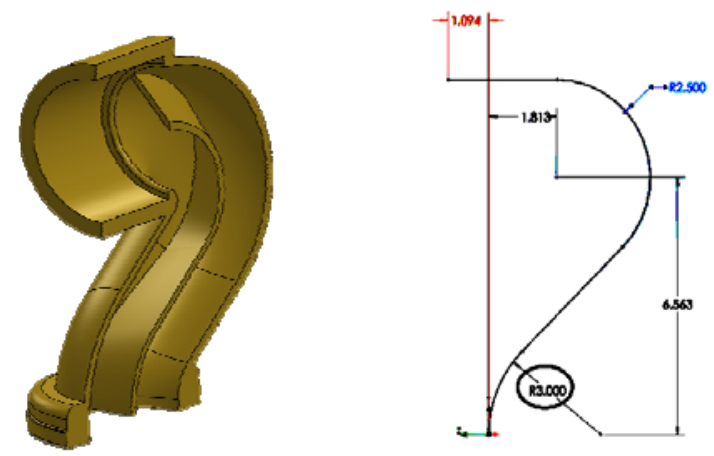

Figure 3. Conceptual model and flow path primitives.

characteristics with the radii of primitive arcs as variables in the mathematical model. Definition of the flow path was established using consecutive arcs in the solid model.

Parametric definition of the arcs were used to generate sweeps for the shell and vane. The final solid model is composed of two flow guide elements, flanged base and flow nozzle. It also includes internal vane along flow path and standard fittings of a monitor. Flow element and assembly are shown in Fig. 3.

\section{DESIGN ANALYSIS}

The final assembly of the solid model for the monitor was utilized to analyze the flow problem using a Computational Fluid Dynamics (CFD) analysis tool available in SolidWorks. A programmed tool was developed to automatically perform this analysis for a series of combination of the flow trajectory radii (Table I and II ) - boldbace for maximum values). Initial analysis was conducted by varying each radius of the flow path trajectory primitive, and a polynomial function was generated relating pressure loss and radius (Fig. 4). It revealed a clear correlation between these two parameters, path radius and pressure loss. For the specific model defined by the constraints established earlier, a specific combination of the path radii reduces the pressure loss to a minimum.

For the definition of the actual combination of radii to specify, 34 different combination of R1 and R2 were specified, and the output pressure and velocity were observed. The goal was to have the highest values for the combination of both parameters. The first radius (R1) was varied from 2.75in to 4.625in, and the second radius (R2) was varied from 2.25in to 3.25in. An input pressure of $100 \mathrm{psi}$ at the entrance of the flow monitor (i.e. lower end) and a 1,000 GPM flow rate of water at $60^{\circ} \mathrm{F}$ were specified. The output pressure (i.e., upper end of the monitor/model) and velocity at the exit were tabulated (see Table I). A summary of the results is presented in Table III, with the corresponding average values indicated for each one of the listed combinations. There is an option highlighted in yellow indicating the current radii parameters, and the option in green indicates the selected option R1 = 3.75in and R2=3.00in). At the selected combination there is capacity for a maximum velocity of $39.569 \mathrm{ft} / \mathrm{s}$, which results

$14^{\text {th }}$ LACCEI International Multi-Conference for Engineering, Education, and Technology: "Engineering Innovations for 


\begin{tabular}{|c|c|c|c|}
\hline \multicolumn{4}{|c|}{ Flow - First Radius } \\
\hline $\begin{array}{c}\text { Config } \\
\#\end{array}$ & $\begin{array}{l}\text { R1 } \\
\text { (in) }\end{array}$ & $\begin{array}{c}\text { Output Pressure } \\
\text { (psi) }\end{array}$ & $\begin{array}{c}\text { Output Velocity } \\
\text { (ft/s) }\end{array}$ \\
\hline & & Overall Avg & Overall Avg \\
\hline 1 & 3.500 & 95.982 & 28.792 \\
\hline 5 & 3.000 & 95.779 & 28.830 \\
\hline 6 & 4.000 & 96.138 & 28.789 \\
\hline 8 & 3.250 & 95.878 & 28.853 \\
\hline 9 & 3.750 & 96.061 & 28.774 \\
\hline 10 & 4.250 & 96.211 & 28.807 \\
\hline 11 & 4.500 & 96.205 & 28.825 \\
\hline 12 & 2.750 & 95.695 & 28.880 \\
\hline 13 & 4.625 & 96.131 & 28.825 \\
\hline
\end{tabular}

TABLE II. OUTPUT PRESSURE AND VELOCITY FOR R2.

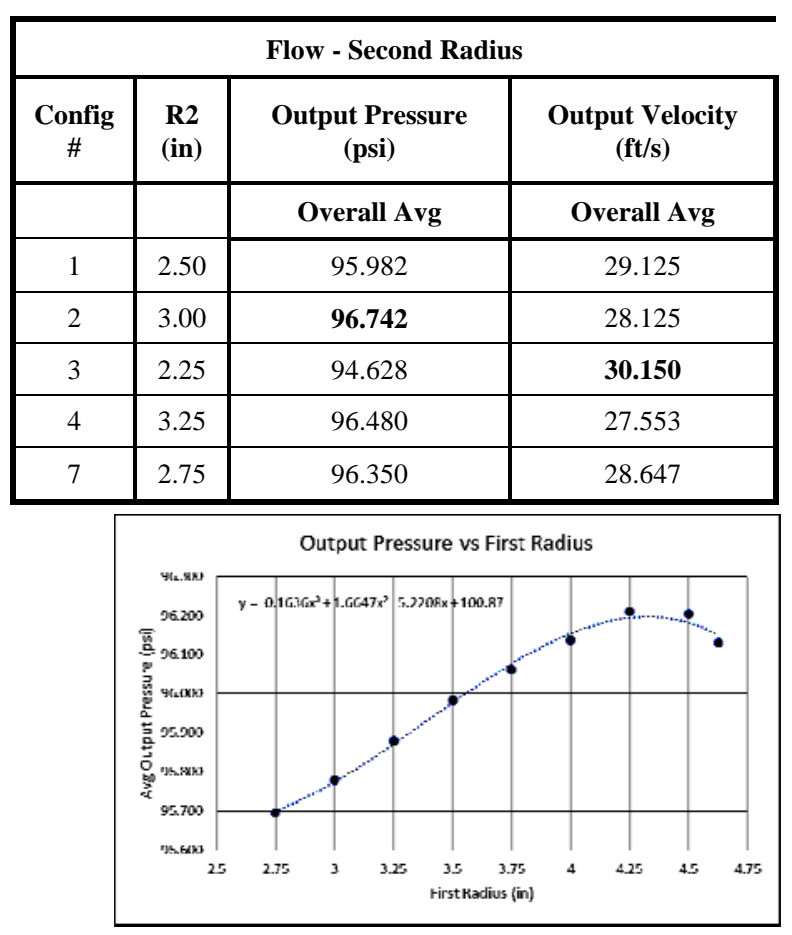

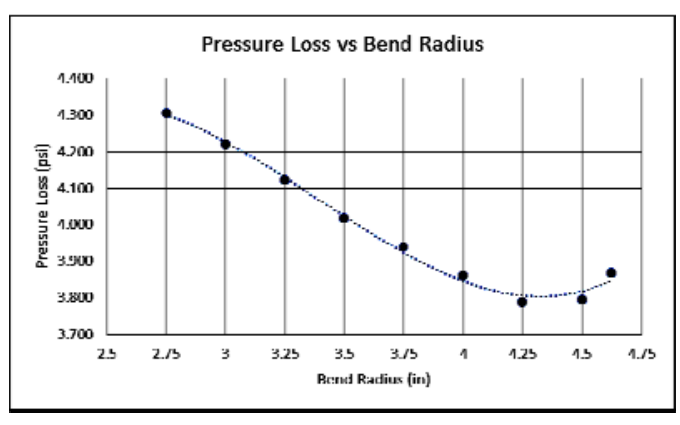

Figure 4. Bend radius, output pressure and pressure loss.

\begin{tabular}{|c|c|c|c|c|}
\hline \multicolumn{5}{|c|}{ Flow Section } \\
\hline $\begin{array}{c}\text { Config } \\
\text { ( } 1\end{array}$ & $\begin{array}{c}\text { R2 } \\
\text { (in) }\end{array}$ & $\begin{array}{c}\text { Output Pressure } \\
\text { (psi) }\end{array}$ & $\begin{array}{c}\text { Output Velocity } \\
\text { (ft/s) }\end{array}$ \\
\hline 14 & 2.750 & 2.25 & Avg & Avg \\
\hline 17 & 2.750 & 3.25 & 96.963 & 30.931 \\
\hline 18 & 3.000 & 2.25 & 94.582 & 27.624 \\
\hline 21 & 3.000 & 3.25 & 96.387 & 30.439 \\
\hline 22 & 3.250 & 2.25 & 94.598 & 27.572 \\
\hline 25 & 3.250 & 3.25 & 96.455 & 30.293 \\
\hline 3 & 3.500 & 2.25 & 94.628 & 25.578 \\
\hline 1 & 3.500 & 2.5 & 95.982 & 30.150 \\
\hline 27 & 3.750 & 2.75 & 96.470 & 28.792 \\
\hline $\mathbf{2 8}$ & $\mathbf{3 . 7 5 0}$ & $\mathbf{3}$ & $\mathbf{9 6 . 7 7 1}$ & $\mathbf{2 8 . 0 5 1}$ \\
\hline 30 & 4.000 & 2.75 & 96.480 & 28.486 \\
\hline 32 & 4.250 & 2.75 & 96.365 & 28.421 \\
\hline 33 & 4.500 & 2.25 & 94.762 & 29.647 \\
\hline 34 & 4.625 & 2.25 & 94.762 & 29.809 \\
\hline
\end{tabular}

in a flow of 3490 gpm (with an average of 2475gpm), more than the specified requirement.

At the established flow conditions, a comparison of the pressure loss between the proposed design and the Stock Scorpion model results in a 34\% improvement. From a 22.311 psi pressure loss in the Stock Scorpion model, to 14.66 psi in the proposed monitor geometry. All the other major conditions are fulfilled. Though in actual testing and operations this improvement is expected to change, it still is a significant improvement over currently available monitors, and it is expected to keep such improvement after the design is in production. To ensure mechanical integrity of the monitor, a Finite Element Analysis (FEA) was performed on stress and deformation of the assembly under most severe operational conditions. Material and mechanical dimensions were updated based on a safety factor of 2 .

As a next phase of the design process, the effect of manufacturing process, machining and surface finish of the monitor needs to be specified. Performance of the system with fluropolymer, ceramic and Teflon impregnated surfaces needs to be studied. Though each surface treatment contributes to further conservation of fluid pressure, each surface treatment adds to the product and manufacturing process cost. This issue was left for future analysis by the designer of the commercial model. After adding all machining and assembly features for support base, nozzle, instrumentation and drive mechanisms in

$14^{\text {th }}$ LACCEI International Multi-Conference for Engineering, Education, and Technology: "Engineering Innovations for 


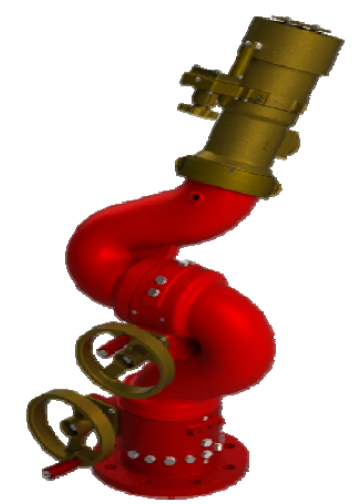

Figure 5. Complete assembly of new model.

the solid model, a complete assembly model for the water monitor is shown in Fig. 5.

\section{CONCLUSIONS}

Taken into account future demand of water monitor in firefighting industry, a larger water monitor with improved performance was designed. Most significant improvement was due to improved flow path trajectory defined by segmented arc primitives. The specified values for flow and output pressure were accomplished. In the CFD analysis, this new design reduces the pressure loss by more than $34 \%$ compared to an existing model. Performance of the system was further improved by use of low friction surface treatment. After its performance testing, this design would be refined prior to commercial production.

\section{REFERENCES}

[1] Elkhart Brass Manufacturing, Monitors Elkhart Brass - Fire Fighting Equipment. Retrieved October 14, 2013, from http://www.elkhartbrass. com/products/monitors.

[2] Akron Brass Storm Monitor and Background Information, Akron Brass Company. http://www.akronbrass.com/monitors/stormtm-monitor-withstyle- 5079-nozzle

[3] Akron Brass StreamMaster II Monitor 2000 GPM, Akron Brass Company, http://www.akronbrass.com/media/pdf/3480_StreamMaster_II .pdf

[4] Williams Fire \& Hazard Control, Direct-Mount Electric Actuated Monitor, http://www.williamsfire.com/product/9856efa4-6389-4178-b9a8 819fc0d1dfcf/Direct-Mount_Electric_Actuated_Monitor.aspx

[5] Williams Fire \& Hazard Control, Model 5 Water Powered Oscillating Monitor - High Flow. http://www.williamsfire.com/product/0b2a662a8183-4b16-8282900eaed98811/Model_5_Water_Powered_Oscillating_ Monitor_-_High_Flow.aspx

[6] Stoops, K. (2013, November 1). Personal interview.

$14^{\text {th }}$ LACCEI International Multi-Conference for Engineering, Education, and Technology: "Engineering Innovations for 